\title{
Thermal creep study in a gas detection microsystem
}

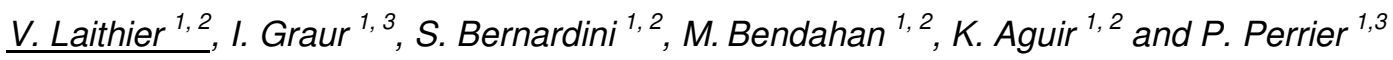 \\ ${ }^{1}$ Aix-Marseille Université, Marseille, France, \\ ${ }^{2}$ CNRS, IM2NP (UMR 7334), Marseille, France, \\ Corresponding author: sandrine.bernardini@im2np.fr \\ ${ }^{3}$ CNRS, IUSTI (UMR 7343), Marseille, France.
}

\begin{abstract}
Our research work aims to develop a gas detection fluidic microsystem. The proposed microsystem is composed of a gas microsensor inserted into a microchannel. By the microsensor heater, a pumping is created due to the thermal creep effect. Thus, the gas is led to the sensor with a controlled flow rate. The study of the pumping effect generation has been realized by thermal and microfluidic simulations. Firstly, the microsystem thermal simulations have been performed to choose the most adapted material to obtain a sufficient thermal gradient and to estimate it along the microchannel. Then, the microfluidic model has been done using these results. These simulations let us to determine the mass flow rate values for different thermal gradient profiles.
\end{abstract}

Key words: Gas sensor, Microfluidic, Gas detection, Thermal creep, $\mathrm{WO}_{3}$,

\section{Introduction}

All control laboratories manipulate constantly standards gas analyzers for the atmospheric pollutants control. These devices are precise to determine the concentration and the nature of gas samples, but they are bulky, slow, and very expensive. New analyze microsystems can solve these drawbacks but need an external pumping $[1,2,3]$. Our work targets to develop and fabricate new microdevice gas detection with an integrated pumping system. Thus, we use the heater microsensor to generate a thermal pumping thanks to the thermal creep phenomenon. Firstly, we describe the microsystem and the main study parameters. Then, thermal simulations are explained. Finally, the microfluidic calculations to determine the mass flow rates are exposed.

\section{Microsystem description}

Our microsystem is composed of a $\mathrm{WO}_{3}$ based microsensor with an integrated heater which is inserted into a microchannel with rectangular cross section.
This microsensor has been studied in previous works [4, 5]. Platinum electrodes, a platinum heating resistance and a sensitive thin film were set down on a Pyrex substrate. The platinum layer is $100 \mathrm{~nm}$ and was deposited by magnetron rf sputtering. The $\mathrm{WO}_{3}$ layer is $80 \mathrm{~nm}$ and was deposited by reactive magnetron rf sputtering with a argon/oxygen ratio mixture equal 1 [6].

The sensor heating needed for its response performance is also used for the gas pumping inside the microchannel. The thermal gradient created by the heater is needed for the gas transport inside. The gas movement due to the temperature gradient is called the thermal creep (fig.1).

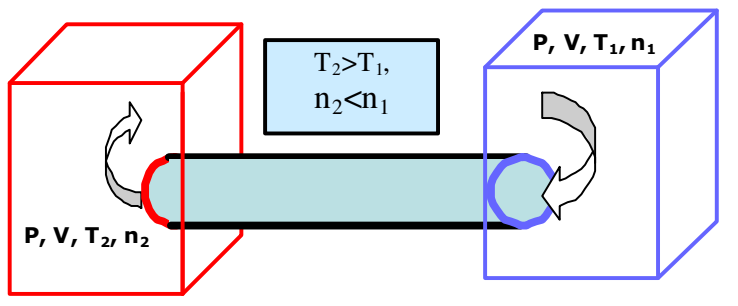

Fig. 1. Thermal creep phenomenon into a 
microchannel.

To obtain this phenomenon two conditions are very important: the gas flow regime inside the channel and the temperature difference between the channel's ends [7]. In order to respect this first condition the channel height was chosen to be equal to $10 \mu \mathrm{m}$. According to this choice the gas inside the microchannel is in the Slip flow regime under the atmospheric pressure conditions. The microchannel width was determined to be equal to $500 \mu \mathrm{m}$ to insert the microsensors inside the microchannel extremity (see fig. 2). The length choice was relied both to the value of the temperature gradient whished and the flow rate estimation. These dimensions are chosen to obtain the best microsystem functioning [4]. The details of these parameters are presented in the next parts of this paper.

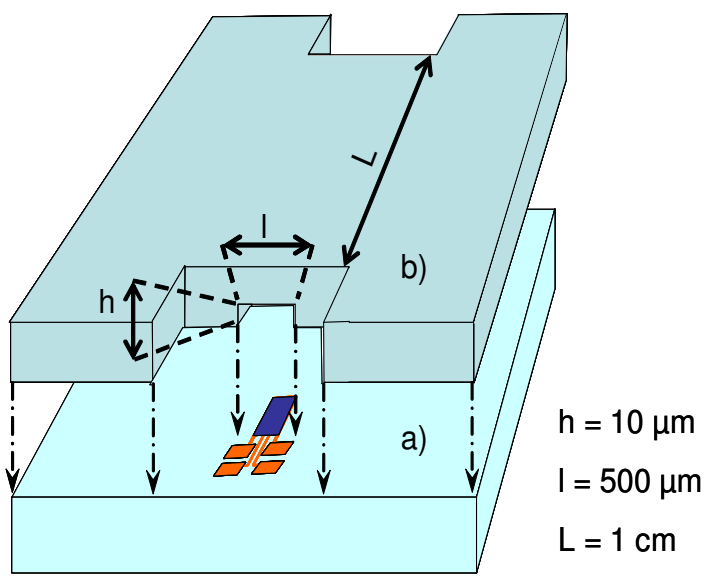

Fig. 2. Microsystem description.

\section{Thermal study}

In this part the thermal gradient into the microchannel is studied. Several thermal simulations using Comsol Multiphysics software were performed to determine the gradient temperature profile along the microchannel (fig. 3).

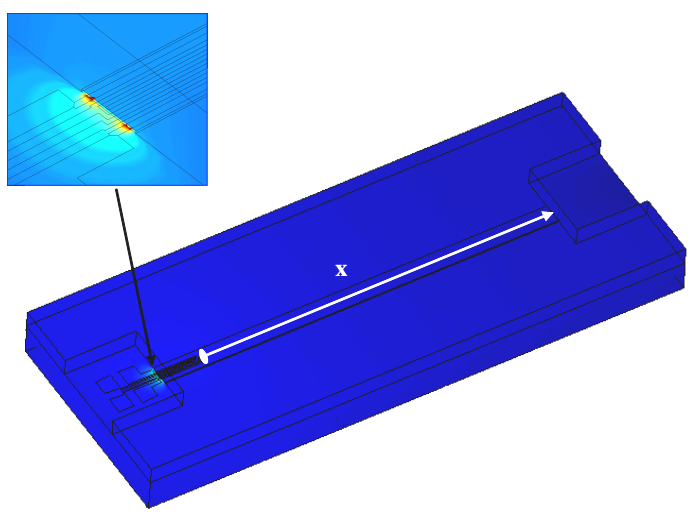

Fig. 3. Axe direction of the thermal gradient along the microchannel

Firstly, we tested two materials with different thermal properties (silicon and Pyrex) to determine the best materials for the microsensor substrate.

A geometric model was drawn from the dimensions chosen (see section "Microsystem description"). The substrate was defined as a simple block of $700 \mu \mathrm{m}$ thick and then the heater and the platinum electrodes are "extruded" on the substrate by the simulator. The more complex step was to fix the platinum properties. Indeed, metals are not the same properties in thin film compared to the bulk.

Thanks to the heater calibration and electric tests, we could determine the electric conductivity and from the Wiederman-Franz equation as eq. (1) we could know the thermal conductivity where $\angle$ is the Lorentz number.

$$
\begin{aligned}
& \frac{\lambda}{\sigma}=\frac{\pi^{2}}{3}\left(\frac{k_{B}}{e}\right)^{2} T=\angle \times T \\
& \angle=\frac{\pi^{2} k^{2}}{3 e^{2}}=2.45 .10^{-8} \text { W.S.K }{ }^{-1} .
\end{aligned}
$$

The values used for the platine heater model are presented in table 1 for five temperatures. Thermal conductivity and Electrical conductivity are significant parameters because the simulations require the electric bias of the platinum heater. This choice permits to define, with the best approximation, the microsystem thermal repartition. For the simulation, several potential values were applied across the heater. Thus several heating temperatures were simulated. 


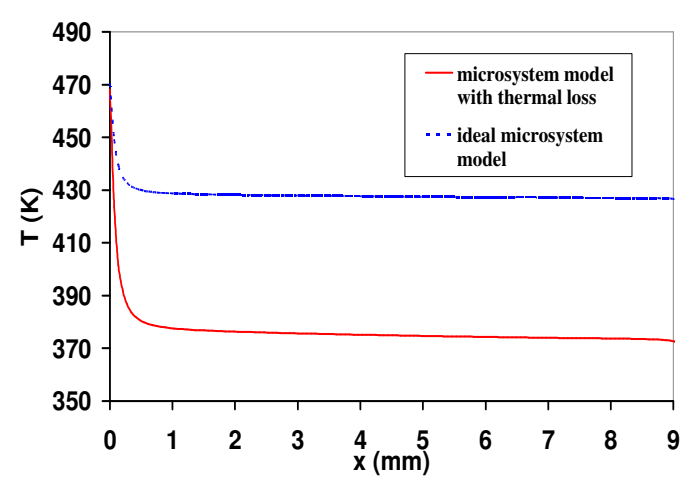

Fig. 4. Thermal profiles simulated for an ideal microsystem model and a microsystem model with thermal losses.

\begin{tabular}{|c|c|c|c|}
\hline $\begin{array}{c}\mathbf{T} \\
\mathbf{( K )}\end{array}$ & $\begin{array}{c}\text { Thermal } \\
\text { conductivity } \\
(\text { W.mK }\end{array}$ & $\begin{array}{c}\text { Electrical } \\
\text { conductivity } \\
\text { standard } \\
\text { values }\end{array}$ & $\begin{array}{c}\text { Thermal } \\
\text { experimental } \\
\text { values } \\
\left.\text { (W.m. } \mathrm{m}^{-1}\right) \\
\text { experimental } \\
\text { values }\end{array}$ \\
\hline $\mathbf{2 9 3}$ & 71.5 & $3.8410^{6}$ & 27.5 \\
\hline $\mathbf{3 7 3}$ & 71.5 & $3.2910^{6}$ & 30.0 \\
\hline $\mathbf{4 7 3}$ & 72 & $2.7810^{6}$ & 32.2 \\
\hline $\mathbf{5 7 3}$ & 72.8 & $2.4110^{6}$ & 33.9 \\
\hline $\mathbf{6 7 3}$ & 73.8 & $2.2610^{6}$ & 35.1 \\
\hline
\end{tabular}

Tab. 1. Standard and measured thermal and electrical conductivities of platinum, at different temperatures.

Pyrex and silicon materials were tested to define the support and the cover of the microsystem model. The first one is the silicon. It has an important thermal conductivity $\left(82.3 \mathrm{~W} \cdot \mathrm{mK}^{-1}\right.$ at $\left.473 \mathrm{~K}\right)$. The second one is the Pyrex which has a low conductivity $\left(1.4 \mathrm{~W} \cdot \mathrm{mK}^{-1}\right.$ at $\left.473 \mathrm{~K}\right)$.

In the first case, the thermal diffusion in the silicon substrate was too high to obtain a sufficient gradient. In the second case, an important gradient along the Pyrex substrate can be obtained. Thus, this material was chosen to the microsensor support.

Then, the cover geometry including the microchannel was drawn and added to the Pyrex support with the Comsol multiphysics software. The key parameter is the microchannel height. Due to its thin value (10 $\mu \mathrm{m})$ compare to the cover one, this parameter complicates the calculation. Indeed, it will require a specific mesh which induces time consuming simulations. Moreover, to simplify the model, the heater was defined in $2 \mathrm{D}$ and couldn't be biased by an electric potential. Therefore, its temperature was fixed.
Simulation results prove that this assumption doesn't influence the gradient result. To begin, we considered the back face thermal isolated. However, simulations of this ideal microsystem model didn't match the reality. Thus, the thermal losses through this back face were included (see fig. 4). The results comparison show the influence of this parameter.

The microchannel will be etched in a cover. This one can be in silicon or Pyrex. The both cases were tested. The thermal profiles demonstrate that both cases are possible.

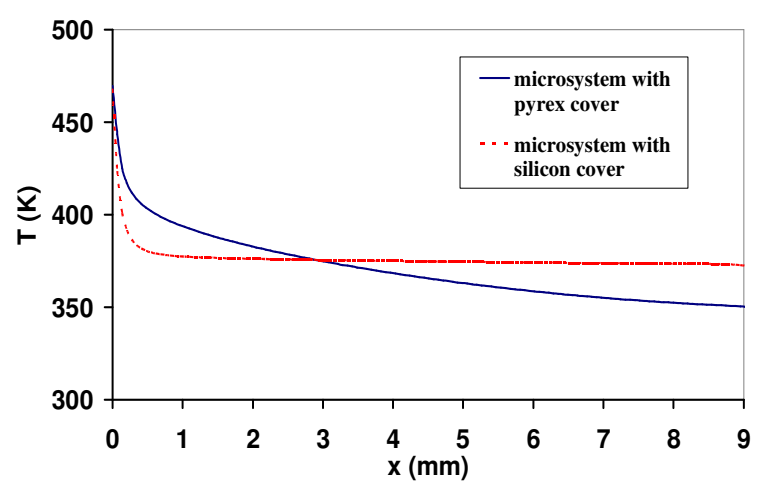

Fig. 5. Thermal profiles along the microchannel simulated with a Pyrex cover and a silicon cover.

Along the microchannel, the temperature decreases regularly for Pyrex cover and the thermal gradient is higher than for the silicon cover (fig.5). Nevertheless, the microsystem processing is easier and less expansive with silicon. To understand the influence of the delta $\mathrm{T}$ and the thermal gradient profile, microfluidic analyses were performed. By fitting these profiles, we found the best equation describing the temperature variations along the microchannel. Then, this equation was taken into account in the microfluidic model.

\section{Microfluidic study}

In order to estimate the mass flow rate through the microchannel, the numerical simulations were carried out using the compressible Navier-Stokes equations subjected the velocity slip boundary conditions and temperature jump boundary conditions [8]. The temperature profiles along the channel's wall were taken from simulation descried in the Section "Thermal study" where the Comsol multiphysics software was used. Two different materials are studied for the channel cover, silicon and Pyrex. The temperature distribution obtained from the simulation for these two 
materials are used as the boundary conditions for the microfluidic part, see Table 2. Three heater temperatures are studied.

\begin{tabular}{|l|c|c|c|}
\hline $\begin{array}{l}\text { Heater } \\
\text { temperature }\end{array}$ & 473 & 573 & 623 \\
\hline $\begin{array}{l}\text { Mass flow rate } \\
\text { with a silicon } \\
\text { cover } \\
\left.\text { (10 }^{-12} \mathrm{~kg} / \mathrm{s}\right)\end{array}$ & 2.42 & 3.90 & 4.69 \\
\hline $\begin{array}{l}\text { Mass flow rate } \\
\text { with a Pyrex } \\
\text { cover } \\
\left(10^{-12} \mathrm{~kg} / \mathrm{s}\right)\end{array}$ & 2.47 & 5.53 & 7.12 \\
\hline
\end{tabular}

Tab. 2. Mass flow rate calculated for both covers.

For the lower temperature of the heater the mass flow rates through the channels with silicon and Pyrex covers have the similar values. But when the heater temperature increases until $623 \mathrm{~K}$ the mass flow rate through the channel with Pyrex cover is 1.5 larger than for silicon cover.

The Pyrex cover seems to be more adapted, because the larger mass flow rate allows a better quality of the pollution analysis.

\section{Conclusion}

The thermal and microfluidic studies let us estimate the best materials for our gas sensor microsystem. Using Comsol Multiphysics software, simulations were done to evaluate thermal gradient along the microchannel. The thermal simulations confirmed the temperature gradient existence and therefore the thermal creep phenomenon. Thermal and microfluidic simulations indicated that Pyrex is the best material for both the substrate and the channel cover. However due to process technologies for etching, silicon was used as the first cover and later the cover was realized with Pyrex.

\section{Acknowledgements}

The authors gratefully acknowledge this work for financial support in their research by the funding from "Region PACA - BDE n ${ }^{\circ} 648$ " and "Seres Environnement" company and from European Community's Seventh Framework Program (ITN - FP7/2007-2013) under grant agreement $n^{\circ} 215504$.

\section{References}

[1] S-I. Ohira, K. Toda, Analytica Chimica Acta 619, "Micro gas analyzers for environmental and medical applications", 143-156 (2008); doi:10.1016/j.aca.2008.05.010

[2] D. Erickson, D. Li, "Integrated microfluidic devices ", Analytica Chimica Acta 507, 11-26 (2004); doi: 10.1016/j.aca.2003.09.019

[3] L. Zhu, D. Meier, Z. Boger, C. Montgomery, S. Semancik, D.L. DeVoe, "Integrated microfluidic gas sensor for detection of volatile organic compounds in water", Sensors and Actuators $B$ 121, 679-688 (2007); doi: $10.1016 /$ j.snb.2006.03.023

[4] V. Martini, S. Bernardini, M. Bendahan, K. Aguir, P. Perrier and I. Graur., "Fabrication and characterization of gas detection microfluidic", Procedia Engineering 5, 1188-1191 (2010); doi: 10.1016/j.proeng.2010.09.324

[5] V. Martini, S. Bernardini, M. Bendahan, K. Aguir, P. Perrier and I. Graur., "Microfluidic gas sensor with integrated pumping system", Sensors and Actuators B: Chemical (in proof ) (2010) doi:10.1016/j.snb.2011.01.011

[6] R. Boulmani, M. Bendahan, C. LambertMauriat, M. Gillet, K. Aguir, "Correlation between rf-sputtering parameters and WO3 sensor response towards ozone", Sensors and Actuators B, 125., 622-627 (2007); doi: 10.1016/j.snb.2007.03.011

[7] S. Colin and L. Baldas, "Effets de raréfaction dans les micro-écoulements gazeux ", $C$. $R$. Physique 5, 521-530 (2004); doi:10.1016/j.crhy.2004.04.005

[8] J.G. Méolans, I. Graur, "Continuum analytical modelling of thermal creep", European Journal of Mechanics B/Fluids 27, 785-809 (2008); doi:10.1016/j.euromechflu.2008.01.005 